IP $\rightleftharpoons$ B

\title{
Germinação de sementes de duas espécies da caatinga sob déficit hídrico e salinidade
}

\author{
Cibele Alves dos Santos ${ }^{1 *}$, Natália Vaz da Silva ${ }^{1}$, Letícia Siqueira Walter ${ }^{1}$, Elaine Cristina Alves da Silva ${ }^{1}$, \\ Rejane Jurema Mansur Custódio Nogueira ${ }^{1}$
}

${ }^{1}$ Universidade Federal Rural de Pernambuco, Rua Dom Manoel de Medeiros, s/n, CEP 52171-900, Recife, PE, Brasil

"Autor correspondente:

cibelealves.ufrpe@gmail.com

Termos para indexação:

Poincianella pyramidalis

Anadenanthera colubrina

Desenvolvimento de plantas

\section{Index terms:}

Poincianella pyramidalis

Anadenanthera colubrina

Plant development

Histórico do artigo:

Recebido em 20/08/2015

Aprovado em 11/08/2016

Publicado em 30/09/2016

doi: 10.4336/2016.pfb.36.87.1017
Resumo - Plantas que precisam se desenvolver em solos de regiões áridas e semiáridas podem encontrar solos salinizados ou com baixa disponibilidade hídrica. Neste contexto, a presente pesquisa objetivou avaliar a germinação de sementes de catingueira e angico submetidas a condições de estresse salino, induzido pelos cloretos de cálcio e de sódio e à deficiência hídrica, induzida pelo PEG 6000, em substrato rolo de papel. Os tratamentos foram: $0 \mathrm{MPa}$ (controle - água destilada), $-0,4 \mathrm{MPa}\left(\mathrm{NaCl}, \mathrm{CaCl}_{2} \mathrm{e}\right.$ PEG), -0,8 MPa ( $\mathrm{NaCl}, \mathrm{CaCl}_{2}$ e PEG) e -1,2 MPa ( $\mathrm{NaCl}, \mathrm{CaCl}_{2}$ e PEG). Avaliou-se o percentual de germinação, o índice de velocidade de germinação e o tempo médio de germinação. Não houve germinação das sementes de ambas as espécies no potencial osmótico mais negativo (-1,2 MPa) de $\mathrm{CaCl}_{2}$ e de PEG 6000. Foi verificado também que a germinação das duas espécies foi mais afetada pelo $\mathrm{CaCl}_{2}$, não havendo germinação a partir de $-0,8 \mathrm{MPa}$. As sementes de catingueira evidenciaram maior tolerância ao estresse salino, enquanto que as sementes de angico suportaram melhor a condição de deficiência hídrica.

\section{Seeds germination of two caatinga species under drought and salinity}

\begin{abstract}
Plants that need to grow in soils of arid and semi-arid regions can find saline or low water availability soils. The present study aimed at to evaluate germination on roll paper substrate of catingueira and angico seeds under salt and water stress conditions, induced by calcium and sodium chlorides and water stress induced by PEG 6000. Treatments were: $0 \mathrm{MPa}$ (control - distilled water); - $0.4 \mathrm{MPa}\left(\mathrm{NaCl}, \mathrm{CaCl}_{2}\right.$ and PEG), $-0.8 \mathrm{MPa}\left(\mathrm{NaCl}, \mathrm{CaCl}_{2}\right.$ and PEG) and $-1.2\left(\mathrm{NaCl}, \mathrm{CaCl}_{2}\right.$ and $\left.\mathrm{PEG}\right)$. It was evaluate percentage of germination, speed germination index and average germination time. There was no seeds germination of both species under the more negative osmotic potential (-1.2 $\mathrm{MPa}$ ) of $\mathrm{CaCl}_{2}$ and PEG 6000 . Seeds germination of both species were more affected by $\mathrm{CaCl}_{2}$, with no germination over - $0.8 \mathrm{MPa}$. Catingueira seeds showed higher tolerance to salt stress, while angico seeds better withstood water stress condition.
\end{abstract}

\section{Introdução}

A germinação é um dos estágios primordiais do desenvolvimento do vegetal, e durante esta etapa ocorrem processos bioquímicos que têm início a partir da embebição da semente (Barrôco et al., 2005). Para considerar uma semente como germinada, há dois principais critérios de germinação: o critério botânico, que considera germinada a semente que emitiu uma das partes do embrião para fora do envoltório, como por exemplo a emissão da radícula, e o critério tecnlógico , que considera a germinação como a formação de todas as partes da plântula (Ferreira \& Borghetti, 2004; Marcos Filho, 2005).

Para que uma semente germine, a presença da água é essencial e a sua escassez é uma das adversidades 
encontradas por espécies de plantas que se desenvolvem em ambientes secos, uma vez que a disponibilidade de água para a semente, assim como a velocidade de absorção, sofre influência direta da diferença de potencial hídrico entre a semente e o solo (Villela et al., 1991). Portanto, as sementes de espécies que se desenvolvem em solos de regiões áridas e semiáridas encontram situações inadequadas, como por exemplo, solos com elevada concentração de sais ou afetados pela deficiência hídrica, fazendo com que o potencial mátrico do solo seja mais negativo, o que dificulta a absorção de água pela semente (Castro et al., 2004; Guedes et al., 2013).

A concentração de íons no substrato diminui o potencial osmótico do meio, o qual é responsável pelo direcionamento da água, dificultando assim a absorção de água pela semente e o início das fases da germinação (Sarin \& Narayanan, 1968). Além de limitar a absorção da água, o estresse salino também provoca efeitos tóxicos na semente, podendo levar à morte do embrião.

Os efeitos da salinidade sobre a germinação podem ser notados tanto pela interferência dos sais no metabolismo celular, como pela redução do potencial osmótico da semente, causando estresse hídrico e dificultando a absorção de água (Queiroga et al., 2006; Dias \& Blanco, 2010; Silveira, et al., 2010). Segundo Morais et al. (2007), a salinidade pode ainda causar injúrias, como por exemplo degradação das clorofilas e alterações no metabolismo de proteínas e nos teores de aminoácidos, devido ao estresse iônico decorrente da alteração na concentração de íons $\mathrm{Na}^{+}$e $\mathrm{Cl}^{-}$no protoplasma.

Alguns dos principais efeitos são: redução na porcentagem da germinação, baixa velocidade de germinação, redução do crescimento da raiz primária, decréscimo do crescimento do hipocótilo de plântulas e aumento do tempo médio de germinação (Fanti \& Perez, 2004; Machado Neto et al., 2006; Rego et al., 2007; Andréo-Souza et al., 2010; Gordin et al., 2012; Ferreira et al., 2013; Pelegrini et al., 2013).

A catingueira (Poincianela pyramidalis (Tul.) L. P. Queiroz), e o angico (Anadenanthera colubrina (Vell.) Brenan), espécies amplamente distribuídas na Caatinga, pertencem à família Fabaceae e têm importância ecológica e econômica, sendo utilizadas para fins medicinais, madeireiros, forrageiros, ornamentais e para a recuperação de áreas degradadas, dentre outros usos (Carvalho, 2002; Maia, 2012; Saraiva et al., 2012).
A Caatinga vem sendo utilizada pelo homem de forma desordenada, que usufrui de suas árvores para o consumo de frutos, produção de lenha e carvão; e o uso do solo para pecuária e agricultura. Como consequência, milhares de ha já foram desvastados, causando desequilíbrio ambiental, como por exemplo a desertificação em algumas áreas, o que vem despertando o interesse de pesquisadores dos âmbitos ecológico, econômico e social (Velloso et al., 2002; Souza, 2006; Associação Plantas do Nordeste, 2013), para a conservação e o uso sustentável desses recursos.

A pecuária extensiva tem contribuído para a degradação da Caatinga, uma vez que o gado se alimenta das plantas jovens, impedindo que as mesmas se desenvolvam. Aliado a isso, os animais também pisoteiam o solo, comprometendo a drenagem e o escoamento da água, pela compactação (Souza, 2006). Em adição, Cavalcanti (2011) alerta que essa prática compromete o banco de sementes, dificultando a germinação das sementes.

A salinidade é evidenciada na região Nordeste, sendo potencializada pelas altas taxas de evaporação da água presente no solo e também pelo baixo índice pluviométrico, que contribui para o acúmulo de sais na superfície do solo (Lima Junior \& Silva, 2010). Outro agravante é a agricultura irrigada, que quando utilizada múltiplas vezes em áreas degradadas, com água salinizada, comprometem a qualidade do solo e provocam prejuízos econômicos (Ribeiro, 2010).

Diante do cenário atual em que se encontra a Caatinga, e conhecendo a sua importância econômica, social e ecológica, torna-se fundamental ampliar as pesquisas que desenvolvam ações de recuperação ambiental, com o objetivo de promover a recomposição de áreas degradadas ou salinizadas com espécies nativas, a fim de evitar que os impactos causados pelo homem contribuam para processos de degradação do Bioma.

O estudo dos efeitos da salinidade e da deficiência hídrica sobre a germinação de sementes é fundamental para que se compreenda o estabelecimento de espécies vegetais em ambientes salinizados e/ou com pouca água disponível no solo. Portanto, a presente pesquisa objetivou avaliar a germinação de sementes de catingueira e angico submetidas às condições de estresse hídrico e salino. 


\section{Material e métodos}

O experimento foi conduzido no Laboratório de Fisiologia Vegetal do Departamento de Biologia da Universidade Federal Rural de Pernambuco, em junho de 2013. Foram utilizadas sementes de Poincianella pyramidalis (Tul.) L. P. Queiroz e Anadenanthera colubrina (Vell.) Brenan, coletadas de cinco matrizes no município de Crateús, CE em julho de 2012.

Foi realizada a assepsia das sementes por imersão em solução preparada com água destilada e detergente comercial, na proporção de cinco gotas de detergente para cada $100 \mathrm{~mL}$ de água. As sementes permaneceram nessa solução por 5 min e após esse período, passaram por enxágue em água corrente até que a solução com detergente fosse removida por completo (Brasil, 2013).

As sementes foram submetidas a soluções com diferentes potenciais osmóticos, correspondendo ao estresse hídrico induzido pelo polietilenoglicol 6000 (PEG 6000) e ao estresse salino, induzido por cloretos de sódio $(\mathrm{NaCl})$ e de cálcio $\left(\mathrm{CaCl}_{2}\right)$. Para determinar os potenciais osmóticos do PEG, seguiu-se a metodologia descrita por Villela et al. (1991), e para $\mathrm{NaCl}$ e $\mathrm{CaCl}_{2}$, utilizou-se a equação de Van't Hoff, de acordo com Braga et al. (1999).

Os tratamentos utilizados foram: $\mathrm{T}_{1}=0 \mathrm{MPa}$ (Controle - água destilada); $\mathrm{T}_{2}=-0,4 \mathrm{MPa}$ de $\mathrm{NaCl} ; \mathrm{T}_{3}=-0,8$ $\mathrm{MPa}$ de NaCl; $\mathrm{T}_{4}=-1,2 \mathrm{MPa}$ de $\mathrm{NaCl} ; \mathrm{T}_{5}=-0,4 \mathrm{MPa}$ de $\mathrm{CaCl}_{2} ; \mathrm{T}_{6}=-0,8 \mathrm{MPa}$ de $\mathrm{CaCl}_{2} ; \mathrm{T}_{7}=-1,2 \mathrm{MPa}$ de $\mathrm{CaCl}_{2} ; \mathrm{T}_{8}=-0,4 \mathrm{MPa}$ de PEG; $\mathrm{T}_{9}=-0,8 \mathrm{MPa}$ de PEG; $\mathrm{T}_{10}=-1,2 \mathrm{MPa}$ de PEG.

Foi utilizado como substrato o rolo de papel do tipo germitest, sendo utilizadas duas folhas para cada repetição, umedecidas com 2,5 vezes o seu peso. Os rolos foram postos em sacos plásticos transparentes, para se evitar a perda de água por evaporação e que a incidência de luz não fosse comprometida. O teste foi conduzido em germinador do tipo Biochemical Oxigen Demand (B.O.D.), à temperatura de $25^{\circ} \mathrm{C}$ e luz constante.

O delineamento experimental utilizado foi o inteiramente casualizado, correspondendo a 10 tratamentos com 4 repetições de 25 sementes cada, com 100 sementes em cada tratamento, totalizando 1.000 sementes para cada espécie avaliada.

Para avaliar a porcentagem de germinação $(\% \mathrm{G})$, as sementes foram contadas diariamente a partir da instalação do teste, tendo como critério a emissão de $2 \mathrm{~mm}$ de radícula (Antunes et al., 2011). Para a determinação do tempo de contagem, para as duas espécies, seguiu-se o período recomendado que consta nas Instruções para Análise de Sementes Florestais (Brasil, 2013), que foi de 14 dias para Poincianella pyramidalis e 10 dias para Anadenanthera colubrina.

Para calcular o índice de velocidade de germinação (IVG) foram realizadas contagens diárias e utilizouse a fórmula proposta por Maguire (1962). O tempo médio de germinação (TMG) foi determinado segundo proposto por Edmond \& Drapala (1958).

Os dados obtidos foram submetidos à análise de variância (ANOVA) e as médias comparadas entre si pelo teste de Tukey $(\mathrm{p} \leq 0,05)$. Foi utilizado o software Assistat, versão 7.6 beta (Silva \& Azevedo, 2009).

\section{Resultados e discussão}

Verificou-se que os tratamentos com potenciais osmóticos mais negativos afetaram significativamente a germinação das sementes de ambas as espécies, com maior comprometimento sob efeito do $\mathrm{CaCl}_{2}$ (Tabela 1).

Tabela 1. Porcentagem de germinação $(\% \mathrm{G})$ em sementes de Poincianella pyramidalis (catingueira) e Anadenanthera colubrina (angico), submetidas a diferentes potenciais osmóticos induzidos pelo cloreto de sódio $(\mathrm{NaCl})$, cloreto de cálcio $\left(\mathrm{CaCl}_{2}\right)$ e polietilenoglicol 6000 (PEG).

\begin{tabular}{ccc}
\hline \multicolumn{3}{c}{ Porcentagem de Germinação (\%) } \\
\hline Tratamentos & Catingueira & Angico \\
\hline Controle & $90 \mathrm{aA}$ & $96 \mathrm{aA}$ \\
\hline$-0,4 \mathrm{MPa} \mathrm{NaCl}$ & $79 \mathrm{bAB}$ & $97 \mathrm{aA}$ \\
$-0,8 \mathrm{MPa} \mathrm{NaCl}$ & $70 \mathrm{aB}$ & $51 \mathrm{bC}$ \\
$-1,2 \mathrm{MPa} \mathrm{NaCl}$ & $4 \mathrm{aC}$ & $3 \mathrm{aE}$ \\
$-0,4 \mathrm{MPa} \mathrm{CaCl}$ & $84 \mathrm{aAB}$ & $65 \mathrm{bBC}$ \\
$-0,8 \mathrm{MPa} \mathrm{CaCl}$ & $2 \mathrm{aC}$ & $0 \mathrm{aE}$ \\
$-1,2 \mathrm{MPa} \mathrm{CaCl}$ & $0 \mathrm{aC}$ & $0 \mathrm{aE}$ \\
$-0,4 \mathrm{MPa} \mathrm{PEG}$ & $78 \mathrm{aAB}$ & $75 \mathrm{aB}$ \\
$-0,8 \mathrm{MPa} \mathrm{PEG}$ & $18 \mathrm{bC}$ & $30 \mathrm{aD}$ \\
$-1,2 \mathrm{MPa} P E G$ & $0 \mathrm{aC}$ & $0 \mathrm{aE}$ \\
\hline
\end{tabular}

Letras minúsculas comparam as espécies, e maiúsculas os tratamentos pelo teste de Tukey ao nível de 5\% de probabilidade.

A porcentagem de germinação das sementes de catingueira foi maior nos tratamentos controle $(90 \%)$, $-0,4 \mathrm{MPa}$ de $\mathrm{NaCl}$ (79\%), -0,4 $\mathrm{MPa}$ de $\mathrm{CaCl}_{2}(84 \%)$, $-0,4 \mathrm{MPa}$ de PEG 6000 (78\%) e -0,8 MPa de $\mathrm{NaCl}$ $(70 \%)$. A germinação foi afetada quando as sementes foram expostas aos tratamentos de potenciais osmóticos mais negativos de $-1,2 \mathrm{MPa}$ de $\mathrm{NaCl}(4 \%),-0,8$ e -1,2 $\mathrm{MPa}$ de $\mathrm{CaCl}_{2}(2 \%$ e $0 \%$, respectivamente) e $-0,8$ e 
-1,2 MPa de PEG 6000 (18\% e 0\%, respectivamente), demonstrando que $P$. pyramidalis não possui tolerância aos referidos potenciais (Tabela 1).

Para as sementes de angico, houve alta porcentagem de germinação nos tratamentos controle (96\%) e $-0,4$ $\mathrm{MPa}$ de $\mathrm{NaCl}$ (97\%), sendo afetadas quando expostas a $-0,8$ e -1,2 MPa de $\mathrm{NaCl}$ (51\% e 3\%, respectivamente), $-0,4 \mathrm{MPa}$ de $\mathrm{CaCl}_{2}(65 \%)$ e - 0,4 e -0,8 MPa de PEG 6000 (75\% e 30\%, respectivamente). Não houve germinação sob -0,8 MPa de $\mathrm{CaCl}_{2}$ e -1,2 MPa de $\mathrm{CaCl}_{2}$ e PEG 6000 (Tabela 1).

Ao se comparar as espécies, nota-se que a catingueira mostrou-se mais tolerante aos cloretos de sódio e cálcio que o angico, enquanto este demonstrou ser mais tolerante ao PEG 6000 até a concentração de $-0,8 \mathrm{MPa}$. Vale salientar que a germinação de ambas as espécies foi afetada de forma mais severa pelo cloreto de cálcio.

Os tratamentos que ocasionaram os menores percentuais de germinabilidade foram os $-0,8,-1,0$ e -1,2 Mpa, comprovando que essas concentrações de PEG 6000 proporcionam um efeito mais negativo, corroborando com os resultados obtidos por Antunes et al. (2011). Estes autores avaliaram a porcentagem de germinação em sementes de catingueira submetidas a diferentes potenciais osmóticos $(0,-0,2,-0,4,-0,6,-0,8$, $-1,0$ e -1,2 MPa), induzidos pelo PEG 6000 e observaram que quanto mais negativo o potencial osmótico, menor a $\% \mathrm{G}$.

Ao avaliarem os efeitos do estresse hídrico induzido pelo PEG 6000 e salino induzido pelo $\mathrm{KCl}$, sobre a germinação de $A$. colubrina nos potenciais osmóticos de $0,-0,6,-0,8,-1,0,-1,2$ e -1,4 MPa, Rego et al. (2011) constataram que as sementes expostas a -1,0, -1,2 e -1,4 MPa de PEG não conseguiram germinar, fato também verificado no presente estudo. Esses autores verificaram também que para as sementes tratadas com $\mathrm{KCl}$, apenas os tratamentos $-1,2$ e $-1,4$ tiveram a $\% \mathrm{G}$ afetada, demonstrando dessa forma, que sementes de angico possuem tolerância à salinidade.

Em estudo sobre a germinação de Tabebuia chrysotricha em presença do PEG 6000 em diferentes potenciais osmóticos $(0,-0,2,-0,4,-0,6,-0,8$ e -1,0 MPa), Marques et al. (2004) observaram que os tratamentos com potenciais osmóticos inferiores a $-0,4 \mathrm{MPa}$ apresentaram redução na porcentagem de germinação das sementes.

Com relação ao IVG das sementes de catingueira (Tabela 2), pode ser verificado que foi maior nas sementes umedecidas apenas com água destilada $(\mathrm{IVG}=10,63)$. Os tratamentos mais afetados foram os submetidos aos potenciais osmóticos mais negativos: $-1,2 \mathrm{MPa}$ de $\mathrm{NaCl}$ e -0,8 MPa de PEG com IVG de 0,16 e 0,48 , respectivamente.

Tabela 2. Índice de velocidade de germinação em sementes de Poincianella pyramidalis (catingueira) e Anadenanthera colubrina (angico), submetidas a diferentes potenciais osmóticos induzidos pelo cloreto de sódio $(\mathrm{NaCl})$, cloreto de cálcio $\left(\mathrm{CaCl}_{2}\right)$ e polietilenoglicol 6000 (PEG).

\begin{tabular}{ccc}
\hline \multicolumn{3}{c}{ Índice de velocidade de germinação } \\
\hline Tratamentos & Catingueira & Angico \\
\hline Controle & $10,63 \mathrm{bA}$ & $18,78 \mathrm{aA}$ \\
\hline$-0,4 \mathrm{MPa} \mathrm{NaCl}$ & $6,97 \mathrm{bB}$ & $11,78 \mathrm{aB}$ \\
$-0,8 \mathrm{MPa} \mathrm{NaCl}$ & $3,87 \mathrm{aD}$ & $3,89 \mathrm{aC}$ \\
$-1,2 \mathrm{MPa} \mathrm{NaCl}$ & $0,16 \mathrm{aE}$ & $0,18 \mathrm{aD}$ \\
\hline$-0,4 \mathrm{MPa} \mathrm{CaCl}$ & $5,56 \mathrm{aBC}$ & $4,40 \mathrm{bC}$ \\
\hline$-0,4 \mathrm{MPa} \mathrm{PEG}$ & $4,27 \mathrm{aCD}$ & $0,48 \mathrm{aE}$ \\
$-0,8 \mathrm{MPa} \mathrm{PEG}$ & $5,31 \mathrm{aC}$ & $1,43 \mathrm{aD}$ \\
\hline
\end{tabular}

Letras minúsculas comparam as espécies, e maiúsculas os tratamentos pelo teste de Tukey ao nível de $5 \%$ de probabilidade.

Nas sementes de angico, o tratamento controle apresentou IVG de 18,37 e os menores valores foram constatados nos potenciais osmóticos mais negativos (-1,2 MPa de $\mathrm{NaCl}$ e - $0,8 \mathrm{MPa}$ de PEG). Os tratamentos que foram mais afetados foram os que estavam sob condição salina induzida pelo $\mathrm{CaCl}_{2}$, não havendo germinação nos potenciais osmóticos $-0,8 \mathrm{MPa}$ e -1,2 MPa de $\mathrm{CaCl}_{2}$ e -1,2 MPa de PEG.

Rego et al. (2011), submetendo sementes de angico a diferentes potenciais osmóticos induzidos pelo PEG 6000 e KCl, obtiveram resultados de IVG semelhantes ao do presente estudo, com reduções a partir do potencial de $-0,6 \mathrm{MPa}$.

Ao estudar o efeito da salinidade na germinação de sementes de Gallesia integrifolia nos potenciais osmóticos de 0,0, -0,6 e -1,2 MPa, Lopes et al. (2015) verificaram que quando submetidas aos potenciais osmóticos mais negativos, a porcentagem de germinação, assim como o IVG, foram afetados.

Com relação às sementes postas para germinar em condições salinas, verifica-se que nas duas espécies utilizadas o cloreto de cálcio comprometeu mais significativamente o índice de velocidade de germinação. Nassif \& Perez (1997), ao avaliarem a velocidade de germinação em Pterogyne nitens, uma espécie da família Fabaceae, submetida à salinidade pelos cloretos de sódio, cálcio e potássio, observaram que a velocidade de germinação foi mais reduzida nas sementes expostas 
ao $\mathrm{CaCl}_{2}$, fato que também foi verificado na presente pesquisa. Resultados semelhantes também foram encontrados por Braga et al. (1999) em estudo com Enterolobium schomburgkii (Fabaceae), sob salinidade induzida por $\mathrm{NaCl}$ e $\mathrm{CaCl}_{2}$. Os autores verificaram que o cloreto de cálcio afetou de forma mais significativa a $\%$ G e o IVG. Igualmente, Ferreira et al. (2013) também observaram que o $\mathrm{CaCl}_{2}$ tem ação mais prejudicial à germinação e ao vigor de sementes do que o $\mathrm{NaCl}$, ao estudarem o efeitos desses sais em sementes de Cedrela odorata.

Com relação ao TMG da catingueira, as sementes que estavam sob os tratamentos $-1,2 \mathrm{MPa}$ de $\mathrm{NaCl}$ e -0,8 MPa de PEG levaram cerca de 6 e 9,5 dias, respectivamente, para germinarem (Tabela 3 ). Verificase que os tratamentos que germinaram mais rapidamente foram o controle e $-0,4 \mathrm{MPa}$ de $\mathrm{NaCl}$, não havendo diferença estatística entre os mesmos.

Tabela 3. Tempo médio de germinação em sementes de Poincianella pyramidalis (catingueira) e Anadenanthera colubrina (angico), submetidas a diferentes potenciais osmóticos induzidos pelo cloreto de sódio $(\mathrm{NaCl})$, cloreto de cálcio $\left(\mathrm{CaCl}_{2}\right)$ e polietilenoglicol $6000(\mathrm{PEG})$.

\begin{tabular}{ccc}
\hline \multicolumn{3}{c}{ Tempo médio de germinação (Dias) } \\
\hline Tratamentos & Catingueira & Angico \\
\hline Controle & $2,27 \mathrm{aD}$ & $1,49 \mathrm{aC}$ \\
\hline$-0,4 \mathrm{MPa} \mathrm{NaCl}$ & $3,04 \mathrm{aCD}$ & $2,19 \mathrm{aBC}$ \\
$-0,8 \mathrm{MPa} \mathrm{NaCl}$ & $4,85 \mathrm{aBC}$ & $3,48 \mathrm{aABC}$ \\
$-1,2 \mathrm{MPa} \mathrm{NaCl}$ & $6,33 \mathrm{aB}$ & $2,62 \mathrm{bBC}$ \\
\hline$-0,4 \mathrm{MPa} \mathrm{CaCl}$ & $3,89 \mathrm{aCD}$ & $4,32 \mathrm{aAB}$ \\
\hline$-0,4 \mathrm{MPa} \mathrm{PEG}$ & $4,81 \mathrm{aBC}$ & $3,69 \mathrm{aABC}$ \\
$-0,8 \mathrm{MPa} \mathrm{PEG}$ & $9,48 \mathrm{aA}$ & $5,33 \mathrm{bA}$ \\
\hline
\end{tabular}

Letras minúsculas comparam as espécies, e maiúsculas os tratamentos pelo teste de Tukey ao nível de $5 \%$ de probabilidade.

O menor TMG das sementes de angico foi observado nos tratamentos controle e $-0,4 \mathrm{MPa}$ de $\mathrm{NaCl}$, semelhante ao ocorrido nas sementes de catingueira (Tabela 3 ). Os maiores valores de TMG foram observados nos tratamentos -0,8 $\mathrm{MPa}$ de $\mathrm{NaCl}$ e -0,4 $\mathrm{MPa}$ e -0,8 $\mathrm{MPa}$ de $\mathrm{CaCl}_{2}$ e PEG, respectivamente. $\mathrm{O}$ tempo médio de germinação não foi calculado para os tratamentos $-0,8$ e -1,2 $\mathrm{MPa}$ de $\mathrm{CaCl}_{2}$ e -1,2 MPa de PEG, uma vez que as sementes não germinaram.

Observa-se que as sementes de angico levaram menor tempo para germinar do que as sementes de catingueira (Tabela 3). Este resultado se justifica por A. colubrina ter apresentado menor número de sementes germinadas, principalmente nos tratamentos -1,2 $\mathrm{MPa}$ de $\mathrm{NaCl}$ e - 0,8 MPa de PEG.
Ao avaliarem o tempo médio de germinação em sementes de catingueira sob estresse hídrico induzido por polietilenoglicol, Antunes et al. (2011) constataram que nos potenciais de $-0,4$ e - $-0,8 \mathrm{MPa}$ foi necessário um maior número de dias para que as sementes germinassem, dados que corroboram com os resultados obtidos na presente pesquisa.

\section{Conclusões}

As espécies em estudo apresentam tolerância à salinidade e à seca, por germinarem até em condições de potenciais osmóticos de $-0,8 \mathrm{MPa}$ de $\mathrm{NaCl}$ e PEG 6000. Porém, Poncianella pyramidalis se mostrou mais tolerante ao estresse salino induzido pelo $\mathrm{NaCl}$, enquanto que Anadenanthera colubrina, ao estresse hídrico.

$\mathrm{O} \mathrm{CaCl}_{2}$ compromete severamente a germinabilidade tanto das sementes de catingueira quanto de angico.

\section{Referências}

Andréo-Souza, Y. et al. Efeito da salinidade na germinação de sementes e no crescimento inicial de mudas de pinhão-manso. Revista Brasileira de Sementes, v. 32, n. 2, p. 83-92, 2010. DOI: 10.1590/S0101-31222010000200010.

Antunes, C. G. C. et al. Germinação de sementes de Caesalpinia pyramidalis Tul. (catingueira) submetidas a deficiência hídrica. Revista Árvore, v. 35, n. 5, p. 1007-1015, 2011. DOI: 10.1590/ S0100-67622011000600006.

Associação Plantas do Nordeste. A APNE pesquisando a Caatinga em prol da conservação e do manejo florestal sustentado. Disponível em: <http://www.bibliotecaflorestal.ufv. br/handle/123456789/12839>. Acesso em: 27 out. 2013.

Barrôco, R. M. et al. The role of the cell cycle machinery in resumption of postembryonic development. Plant Physiology, v. 137, n. 1, p. 127-140, 2005. DOI: 10.1104/pp.104.049361.

Braga, L. F. et al. Efeito da disponibilidade hídrica do substrato na qualidade fisiológica de sementes de feijão. Revista Brasileira de Sementes, v. 21, n. 2, p. 95-102, 1999.

Brasil. Ministério da Agricultura, Pecuária e Abastecimento. Instruções para análises de sementes florestais. Brasília, DF, 2013. 98 p.

Carvalho, P. E. R. Angico branco. Colombo: Embrapa Florestas, 2002. 10 p. (Embrapa Florestas. Circular técnica, 56).

Castro, R. D. et al. Embebição e reativação do metabolismo. In: Ferreira, A. G. \& Borghetti, F. Germinação: do básico ao aplicado. Porto Alegre: Artmed, 2004. 323 p.

Pesq. flor. bras., Colombo, v. 36, n. 87, p. 219- 224, jul./set. 2016 
Cavalcanti, E. R. Eduação ambiental e educação contextualizada com base na convivência com o semiárido. In: Lima, R. R. C. et al. Desertificação e Mudanças Climáticas no Semiárido Brasileiro. Campina Grande: Instituto Nacional do Semiárido, 2011. p. 79-89.

Dias, N. S. \& Blanco, F. F. Efeitos dos sais no solo e na planta. In: Ghey, H. R. et al. Manejo da salinidade na agricultura: estudos básicos e aplicados. Fortaleza: INCT Sal, 2010. p.130-140,

Edmond, J. B. \& Drapala, W. J. The effects of temperature, sand and soil, and acetone on germination of okra seed. Proceedings of the American Jornal Society for Horticultural Science, v. 71, p. 428-434, 1958.

Fanti, S. C. \& Perez, S. C. J. G. A. Processo germinativo de sementes de paineira sob estresses hídrico e salino. Pesquisa Agropecuária Brasileira, v. 39, n. 9, p. 903-909, 2004. DOI: 10.1590/S0100204X2004000900010.

Ferreira, A. G. \& Borghetti, F. Germinação: do básico ao aplicado. Porto Alegre: Artmed, 2004. 323 p.

Ferreira, E. G. B. S. et al. Processo germinativo e vigor de sementes de Cedrela odorata L. sob estresse salino. Ciência Florestal, v. 23, n. 1, p. 99-105, 2013. DOI: 10.5902/198050988444.

Gordin, C. R. B. et al. Estresse salino na germinação de sementes e desenvolvimento de plântulas de Níger (Guizotia abyssinica (L.f.) Cass.). Acta Botanica Brasilica, v. 26, n. 4, p. 966-972, 2012. DOI: 10.1590/S0102-33062012000400026.

Guedes, R. S. et al. Germinação e vigor de sementes de Apeiba tibourbou submetidas ao estresse hídrico e diferentes temperaturas. Ciência Florestal, v. 23, n. 1, p. 45-53, 2013. DOI: $10.5902 / 198050988438$.

Lima Junior, J. A. \& Silva, A. L. P. Estudo do processo de salinização para indicar medidas de prevenção de solos salinos. Enciclopédia Biosfera, v. 6, n. 11, p. 1-21, 2010.

Lopes, J. C. et al. Germinação e vigor de sementes de pau d'alho sob estresse salino. Pesquisa Florestal Brasileira, v. 35, n. 82, p. 169-177, 2015. DOI: 10.4336/2015.pfb.35.82.631.

Machado Neto, N. B. et al. Deficiência hídrica induzida por diferentes agentes osmóticos na germinação e vigor de sementes de feijão. Revista Brasileira de Sementes, v. 28, n. 1, p. 142-148, 2006. DOI: 10.1590/S0101-31222006000100020.

Maguire, J. D. Speed of germination-aid in evaluation for seedling emergence and vigour. Crop Science, v. 2, n. 2, p. 176-177, 1962.

Maia, G. N. Caatinga: árvores e arbustos e suas utilidades. 2. ed. Fortaleza: Printcolor, 2012. 413 p.

Marcos Filho, J. Fisiologia de sementes de plantas cultivadas. Piracicaba: FEALQ , 2005. 495 p. (FEALQ. Biblioteca de Ciências Agrárias Luiz de Queiroz, 12).

Marques, M. A. et al. Comportamento germinativo de sementes de ipê-amarelo [(Tabebuia chrysotricha (Mart.) Standl.] secadas em câmara seca, armazenadas em diferentes ambientes e submetidas a sete níveis de potencial osmótico. Científica, v. 32, n. 2, p. 127-133, 2004. DOI: 10.15361/1984-5529.2004v32n2p127-133.

Morais, D. L. et al. Acumulação de íons e metabolismo de $\mathrm{N}$ em cajueiro anão em meio salino. Revista Brasileira de Engenharia Agrícola e Ambiental, v. 11, n. 2, p. 125-133, 2007. DOI: 10.1590/ S1415-43662007000200001.
Nassif, S. M. L. \& Perez, S. C. J. G. A. Germinação de sementes de amendoim-do-campo (Pterogyne nitens Tul.): influência dos tratamentos para superar a dormência e profundidade de semeadura. Revista Brasileira de Sementes, v. 19, n. 2, p. 171-178, 1997. DOI: 10.17801/0101-3122/rbs.v19n2p171-178.

Oliveira, A. M. et al. Salinidade na germinação e desenvolvimento de plântulas de aroeira (Myracroduon urundeuva FR ALL). Caatinga, v. 20, n. 2, p. 39-42, 2007.

Pelegrini, L. L. et al. Efeito do estresse hídrico simulado com $\mathrm{NaCl}$, manitol e PEG (6000) na germinação de sementes de Erythrina falcata Benth. Ciência Florestal, v. 23, n. 2, p. 511-519, 2013. DOI: $10.5902 / 198050989295$.

Queiroga, R. C. F. et al. Germinação e crescimento inicial de híbridos de meloeiro em função da salinidade. Horticultura Brasileira, v. 24, n. 3, p. 315-319, 2006.

Rego, S. S. et al. Estresse Hídrico e Salino na Germinação de Sementes de Anadenanthera colubrina (Veloso) Brenan. Journal of Biotechnology and Biodiversity, v. 2, n. 4, p. 37-42, 2011.

Rego, S. S. et al. Influência de potenciais osmóticos na germinação de sementes de Anadenanthera colubrina (Veloso) Brenan (Angicobranco) - Mimosaceae. Revista Brasileira de Biociências, v. 5, supl. 2, p. 549-551, 2007.

Ribeiro, M. R. Origem e classificação dos solos afetados por sais. In: Ghey, H. R. et al. Manejo da salinidade na agricultura: estudos básicos e aplicados. Fortaleza: INCT Sal, 2010. p.11-19.

Saraiva, A. M. et al. Antimicrobial activity and bioautographic study of antistaphylococcal components from Caesalpinia pyramidalis Tull. Brazilian Journal of Pharmaceutical Sciences, v. 48, n. 1, p. 147-154, 2012. DOI: 10.1590/S1984-82502012000100016.

Sarin M. N. \& Narayanan, A. Effects of soil salinity and growth regulators on germination and metabolism of wheat. Physiologia Plantarum, v. 21, p. 1201-1209, 1968. DOI: 10.1111/j.13993054.1968.tb07350.x.

Silva, F. A. S. \& Azevedo, C. A. V. Principal components analysis in the software Assistat-Statistical Attendance. In: WORLD CONGRESS OF COMPUTERS IN AGRICULTURE AND NATURAL RESOURCES, 7, 2009, Reno. St. Joseph: American Society of Agricultural and Biological Engineers, 2009.

Silveira, J. A. G. et al. Mecanismos biomoleculares envolvidos com a resistência ao estresse salino em plantas. In: Ghey, H. R. et al. Manejo da salinidade na agricultura: estudos básicos e aplicados. Fortaleza: INCT Sal, 2010. p.161-179.

Souza, M. J. N. A problemática ambiental: cenários para o Bioma Caatinga no Nordeste do Brasil. In: Silva, J. B. et al. Panorama da geografia brasileira. São Paulo: Annablume, 2006. v. 2. 308 p.

Velloso, A. L. et al. Ecorregiões propostas para o Bioma Caatinga. Recife: Associação Plantas do Nordeste; Instituto de Conservação Ambiental The Nature Conservancy do Brasil, 2002. 76 p.

Villela, F. A. et al. Tabela de potencial osmótico em função da concentração de polietileno glicol 6.000 e da temperatura. Pesquisa Agropecuária Brasileira, v. 26, n. 11/12, p. 1957-1968, 1991. 